El cultivo celular inició su desarrollo a principios del siglo XX (Harrison, 1907; Carrel, 1912) como un método para el estudio del comportamiento de las células animales, libre de las influencias sistémicas que se producen tanto en la homeostasis normal como en el estrés de un experimento.

En los años cincuenta esta técnica entró en una fase de expansión, al dejar de cultivar tejidos resecados para cultivar células dispersas.

Aunque en los inicios Harrison utilizó la rana como fuente de tejidos, por ser un animal de sangre fría, que no requería incubación, el estímulo de la medicina orientó el cultivo celular a los vertebrados, y sobre todo a los mamíferos, puesto que lo que acontece en sus células se asemeja más a lo que sucede en las del ser humano. La tecnología del ratón transgénico y el conocimiento de la genética de este animal hicieron de él durante un tiempo la especie favorita que, además de tejidos, proporcionaba una amplia variedad de tumores.

La demostración de que los tumores humanos también podían brindar líneas celulares continuas (p. ej., HeLa, Gey et al, 1952) incrementó el interés por el cultivo de células humanas.

Al igual que otras técnicas similares, gran parte de la información sobre el cultivo celular no se ha publicado, se ha ido transmitiendo verbalmente en reuniones, simposios o, más a menudo, durante la convivencia en el trabajo diario de un laboratorio. Pese a ello, se ha acumulado mucha experiencia en este campo.

Dos ramas de la investigación médica han destacado como impulsoras del desarrollo del cultivo celular como una técnica moderna y sofisticada, tal y como hoy la conocemos: la producción de vacunas antivirales y la comprensión de los mecanismos que ocurren o dan lugar al cáncer.

La estandarización de las condiciones de cultivo celular de las diferentes líneas, la comercialización de medios de cultivo, inicialmente con suero, el control de la contaminación mediante el empleo de antibióticos y la manipulación con técnicas de asepsia en campanas de flujo laminar dotadas de lámparas de luz ultravioleta, junto con otros avances en biotecnología, han venido a facilitar la técnica. Gracias a las formulaciones de medios libres de suero que se han comercializado, se ha hecho posible el cultivo de tipos celulares específicos, entre los que se incluyen los queratinocitos y los melanocitos.

El cultivo celular ha desempeñado un papel crucial en los avances en investigación básica que, centrándonos en el campo de la oncología, vendrían a explicarnos por qué una célula se hace maligna, qué mecanismos regulan la muerte celular programada o apoptosis, cómo una célula adquiere la propiedad de la inmortalidad controlada, o lo que es lo mismo, la capacidad de proliferación ilimitada característica del cáncer, y otras propiedades o capacidades de gran importancia, como son la invasividad, la capacidad de metastatizar y la de sobrevivir en otros órganos diferentes del tumor primario (esta supervivencia es la característica que en muchos casos hace letal al cáncer). Estos aspectos, en conjunto, se suelen denominar en la literatura médica como tumorigenicidad. 
También en la investigación aplicada el cultivo celular fue y es una técnica clave, y ha contribuido a la búsqueda de dianas terapéuticas potenciales, algunas de las cuales son hoy día una realidad, al sintetizarse y comercializarse fármacos que se emplean en pacientes oncológicos. También han servido para efectuar ensayos in vitro de muchas moléculas que poseerían actividad contra diferentes tipos de cáncer, permitiendo comprobar desde su mecanismo de acción antitumoral hasta ensayos de citotoxicidad en diferentes líneas celulares, cuantificando múltiples parámetros esenciales para establecer su seguridad y eficacia in vitro.

En la actualidad, en muchos hospitales se dispone de unidades de investigación, dotadas de contenedores de nitrógeno líquido, incubadoras que mantienen constante la temperatura, la humedad y la concentración de CO2, campanas de flujo laminar para cultivo, neveras, refrigeradores y todo un sinfín de instrumentos de biología molecular, que contribuyen a que el cultivo celular sea una técnica asequible y, sobre todo, muy precisa y fiable.

En el presente artículo, queremos resaltar la importancia que pueden tener y están teniendo las aportaciones y observaciones basadas en la técnica del cultivo celular en el abordaje diagnóstico y terapéutico del melanoma.

\section{TÉCNICA DEL CULTIVO CELULAR DE LÍNEAS DE MELANOMA HUMANO}

Fuentes de líneas celulares para cultivo.

Existen multitud de líneas celulares de melanoma humano y también diversas líneas celulares de melanocitos normales. De las que se puede obtener comercialmente, existen dos principales bases de datos. La más importante es la American Type Culture Collection (ATCC), y la segunda es la European Collection of Animal Cell Cultures (ECACC). La ATCC suministra, entre sus diversos productos biotecnológicos patentados (microorganismos, líneas celulares y material molecular genómico), líneas celulares de células normales y de células tumorales, entre las que destacaremos, en relación con el propósito de este artículo, diversas líneas de melanoma, con datos exhaustivos sobre su potencial metastatizante y sus condiciones de conservación y cultivo.

La página web de la ATCC es http://www.lgcpromochem-atcc.com y en ella las líneas celulares se muestran con dos designaciones, la original y la del número con el que está registrada en la ATCC. Nuestro grupo cultiva la línea A-375, cuyo número de la ATCC es CRL-1619, y en la base de datos, además de su precio, grado de bioseguridad y depositarios, podemos encontrar el organismo del que procede (humano en nuestro ejemplo), sus propiedades de crecimiento (adherente), órgano y enfermedad de procedencia (piel, melanoma maligno), tumorigenicidad, perfil ADN, análisis citogenético, edad y sexo, propagación (características del medio de crecimiento) y protocolo de cultivo, condiciones de preservación (mantenimiento en congelación), productos o líneas celulares 
relacionadas y referencias de la literatura médica. La homóloga europea, la ECACC, suministra similar información en su página web (http://www.ecacc.org.uk).

Las líneas de melanocitos normales pueden obtenerse mediante Clonetics Corp., San Diego CA, EE.UU., que es la empresa biotecnológica líder en el suministro de células humanas normales para cultivo.

Además, entre los investigadores de diferentes grupos muchas veces se intercambian líneas celulares no patentadas, pero ampliamente utilizadas en investigación y que han dado lugar a multitud de trabajos en la literatura médica. En el Instituto de Investigaciones Biomédicas Alberto Sols se utiliza la línea de melanoma humano M14, traída de Roma por la Dra. Calcabrini, colaboradora de uno de los grupos de investigación de ese centro. Existe una amplia información acerca de sus características de propagación y mantenimiento, y se puede encontrar múltiples referencias en la literatura médica, basadas en su cultivo desde hace muchos años.

Otra fuente de líneas celulares es la clínica. El Servicio de Oncología del Complejo Hospitalario Universitario Juan Canalejo ha puesto a nuestra disposición una línea de melanoma humano obtenida de un derrame pleural metastásico de un paciente con melanoma maligno. Aunque ofrece ventajas económicas obvias y no plantea problemas en cuanto a su preservación y mantenimiento, tiene el inconveniente de cierta falta de caracterización en cuanto a tumorigenicidad y experiencia en estudios experimentales, que cuando se completen harán de ella posiblemente una línea muy interesante, pero de momento no podemos predecir su utilidad en cultivo celular. De cualquier manera, las líneas celulares comercializadas y no comercializadas, pero consolidadas en la literatura médica, iniciaron su andadura de un modo similar, por lo que hay que considerar al paciente una fuente de líneas celulares para cultivo de gran interés potencial.

Técnica del cultivo celular de líneas de melanoma

La preservación de las líneas celulares de melanoma se lleva a cabo en N2 (nitrógeno líquido), en viales de congelación que contienen las células en una solución al $90 \%$ en FCS (suero bovino fetal) y $10 \%$ de dimetil sulfóxido (DMSO). Este último evita, al menos en parte, la formación de cristales de la solución acuosa (10\% DMSO, $90 \%$ suero bovino fetal) en la que resuspendemos las células que vamos a congelar y es empleado desde finales de los años cincuenta.

El vial que queremos cultivar se descongela rápidamente y se lavan las células en el medio de cultivo para eliminar el DMSO que puede resultar citotóxico. En nuestro caso el medio de cultivo empleado es RPMI complementado con $10 \%$ FCS (suero bovino fetal), $1 \%$ penicilina-estreptomicina y $1 \%$ glutamina (comercializado por Gibco, Grand Island, Nueva York). A continuación se siembran en este medio en placas petri de cultivo celular. Cuando la densidad celular alcanza el $80 \%$, los cultivos se expanden, generalmente en una relación 1:3 $\circ$ 1:4. Estas manipulaciones se realizan en condiciones de esterilidad en 
campanas de flujo laminar. Dado que estas células se adhieren a la placa en la que se cultivan, en primer lugar se aspira el medio de cultivo y se lavan las células con una solución salina tamponada que contiene agentes quelantes de calcio para facilitar su suspensión. A continuación se incuban con una solución tamponada de tripsina. Una vez en solución, las células se diluyen en medio de cultivo y se siembran en las nuevas placas.

Cuando se realiza un experimento, las células se tratan con la sustancia adecuada (inhibidores, estimuladores, etc.), de acuerdo con el protocolo establecido a tal fin. Terminado el período de tratamiento, se aspira el medio de cultivo, se colocan las placas sobre hielo para detener sus respuestas metabólicas y se lavan con una solución salina tamponada, para eliminar los restos de medio de cultivo. A continuación se añade el tampón de lisis celular adecuado para el experimento y se raspan las células, transfiriéndolas a un tubo de ensayo. Tras un período de incubación a $4 \stackrel{\circ}{\circ}$, se centrifuga el lisado, para eliminar los restos celulares no disueltos en el tampón. El sobrenadante se transfiere a otro tubo y se determina su concentración proteica. De esta manera se puede estandarizar lisados de células tratados de forma diversa. Dado que nuestro interés se centra en determinar efectos de estimulación o inhibición de proteínas cinasas, los tratamientos que se suelen realizar son por cortos períodos, entre $5 \mathrm{~min}$ y $1 \mathrm{~h}$. Para determinar el grado de activación o inhibición de estas enzimas, determinamos sus grados de fosforilación específica (grado de activación) y su expresión por técnicas de inmunodetección en membrana (Western blot). Para ello separamos las proteínas de los lisados celulares por electroforesis en geles de poliacrilamida en condiciones desnaturalizantes, transferimos las proteínas del gel a una membrana, que incubamos ulteriormente con anticuerpos específicos para las formas activadas de las enzimas que queremos analizar. Por último, empleando reactivos especiales, revelamos la presencia del anticuerpo unido a la enzima de nuestro interés.

Posibilidades del cultivo de líneas de melanoma humano

Uno de los objetivos prioritarios en investigación en melanoma maligno es el terapéutico, por la pobre respuesta de este cáncer a los tratamientos actuales, clásicamente dacarbazina en monoterapia o bien en poliquimioterapia, por lo que se publican interesantes artículos con moléculas prometedoras basados en las posibilidades que ofrece el cultivo celular. En concreto, con la línea de melanoma maligno humano M14 se han publicado trabajos con derivados del ácido gálico, un producto utilizado como conservante de los alimentos, así como con componentes derivados del mundo vegetal como los terpenos derivados del árbol del té.

Pero, además de los ensayos farmacológicos, ha sido fundamental el estudio de las distintas vías de señalización de las células, que permiten comprender los mecanismos de la transformación maligna y el hallazgo de nuevas dianas terapéuticas. Como ejemplo de ello podemos comentar lo ocurrido con la familia de las metaloproteinasas (MMP), de las cuales se dispone ya de valiosa información, en gran parte obtenida de experimentos de cultivo celular, en relación con las capacidades invasiva y metastatizante del melanoma. Basándose en la 
observación de los inhibidores tisulares de las metaloproteinasas (TIMP), que regulan la producción de estas enzimas mediante inhibición de su síntesis, se desarrollaron inhibidores sintéticos, batimastat y marimastat, con el fin de impedir la metastatización mediante el bloqueo de la actividad de, fundamentalmente, MMP-2 y MMP-9. Batimastat demostró reducir las metástasis de melanoma, carcinoma de mama y colorrectal in vitro e in vivo, pero los ensayos se suspendieron por no poder administrarse por vía oral y por ocasionar numerosos efectos secundarios. Los ensayos con marimastat fueron decepcionantes, puesto que no se consiguió incrementar la supervivencia de pacientes con cáncer gástrico y con cáncer pancreático avanzado.

El cultivo celular ha servido para el estudio del papel de estímulos ambientales, como son las radiaciones ultravioleta (UV), y también el papel de determinados oncogenes, como pueden ser c-Src, v-Raf o Ras, en la malignización y progresión del melanoma. Es bien conocido que la angiogénesis (formación de vasos sanguíneos) es uno de los principales determinantes de la capacidad de proliferación y crecimiento del tumor y también de su capacidad de metastatizar. Se ha visto, mediante estudios experimentales con líneas celulares de melanoma humano, como la WM3515, que la hipoxia, la activación de Ras y la inactivación de p53 (mediante cultivo de líneas p53 dominante negativas) regulan la expresión del factor angiogénico VEGF, lo cual indirectamente indica que se aumentaría la angiogénesis, la cual, al menos según los resultados de ese trabajo, no se ve incrementada por la exposición de los cultivos celulares a radiación UV. La activación de Ras incrementa la expresión de VEGF mediante la vía de las MAP cinasas, y la hipoxia potencia el efecto de la activación de este oncogén. La comprensión de los diversos mecanismos por los cuales las células cultivadas sobreexpresan VEGF, y qué mecanismos están interviniendo en tumores específicos, puede ser de ayuda en el diseño de terapias antitumorales específicas.

Otra de las posibilidades que ofrece el cultivo celular de líneas de melanoma humano es el estudio de marcadores moleculares pronósticos. Actualmente, el pronóstico del melanoma maligno cutáneo humano está basado en parámetros estadísticamente validados, principalmente el grosor del tumor medido por el índice de Breslow, el nivel de invasión (nivel de Clark), la presencia de ulceración y el número de mitosis por mm2. Sin embargo, en diversas publicaciones se viene llamando la atención de que no es un método de pronóstico preciso en todos los casos. Se habla de que entre un 5 y un $22 \%$ de los melanomas finos $(<0,7 \mathrm{~mm}$ de Breslow) evolucionan a enfermedad metastásica y propagación extremadamente rápida, mientras que el $25-50 \%$ de los pacientes cuyos tumores se clasifican como gruesos (> $4 \mathrm{~mm}$ ) inexplicablemente sobreviven a largo plazo, por lo que la búsqueda de marcadores moleculares mediante inmunohistoquímica, técnicas de cultivo celular e incluso mediante microarrays y otras técnicas de detección, como la reacción en cadena de la polimerasa (PCR) en tiempo real, está en marcha, y ya se ha encontrado un buen número de candidatos como marcadores moleculares de mal pronóstico, pero estos resultados necesitan confirmarse en series más amplias de pacientes. 
De consolidarse el empleo de marcadores moleculares de mal pronóstico, se podría pasar a estrategias en las cuales se trataría más agresivamente algunos melanomas de menos de $1 \mathrm{~mm}$ de Breslow, posiblemente con la administración más temprana de quimioterapia, y también podría dar lugar a un cambio de los protocolos quirúrgicos.

Aunque el cultivo celular de líneas de melanoma ofrece otras posibilidades, hemos querido centrarnos en los objetivos prioritarios de la investigación y la utilidad de esta asequible técnica, de modo que si no se consigue su curación, al menos se alcance la meta de muchos grupos de investigación en cáncer: encontrar dianas terapéuticas que nos permitan que el tumor no metastatice y se convierta en una enfermedad crónica más, como la diabetes mellitus o la hipertensión arterial; en resumen, que de no ser curable, al menos no sea necesariamente mortal.

Jesús Rodríguez Lozano, Jorge Martín Pérez y Eduardo Fonseca Capdevila.

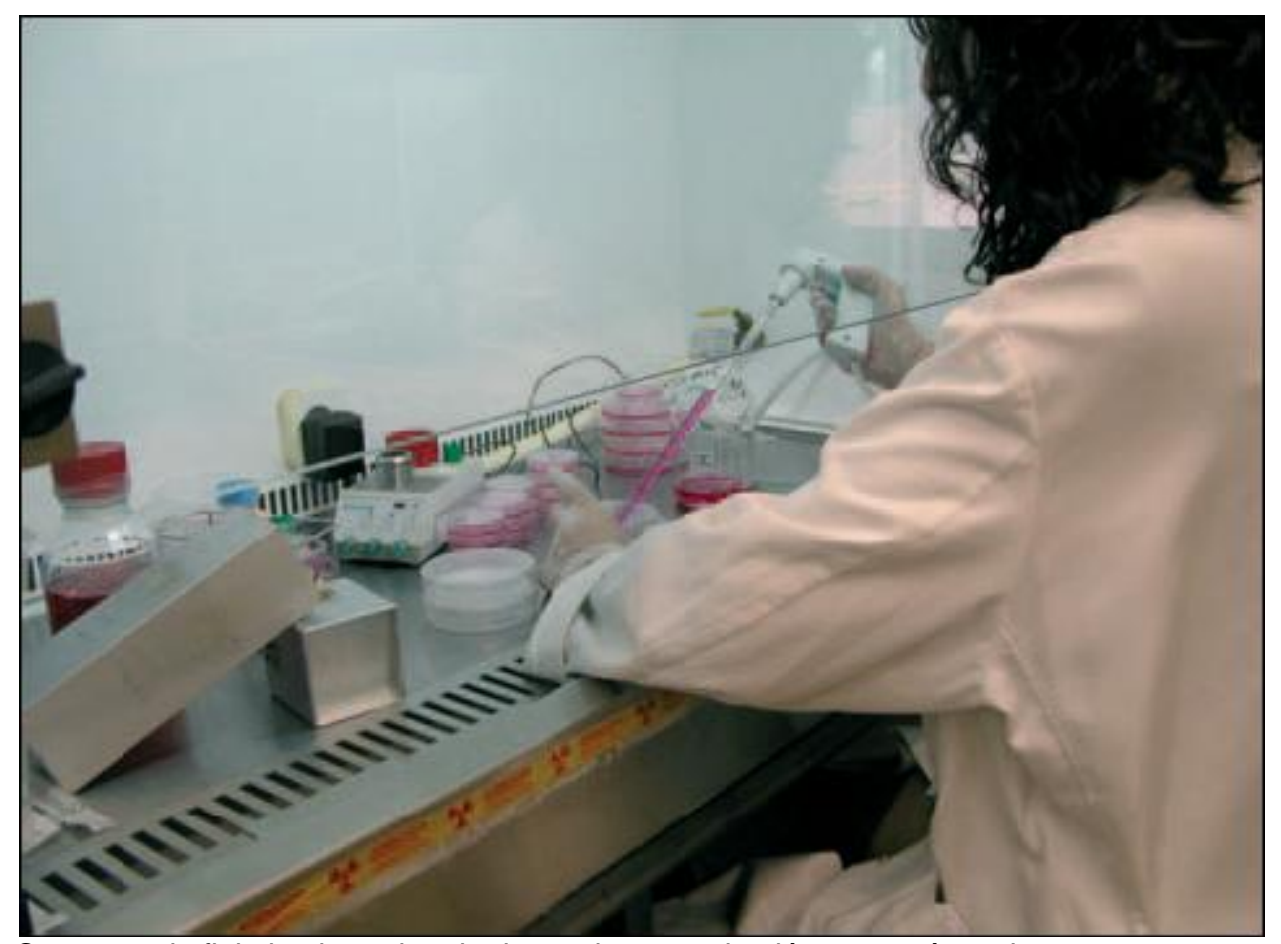

Campana de flujo laminar, dotada de mechero, aspiración por vacío y pipetus. 


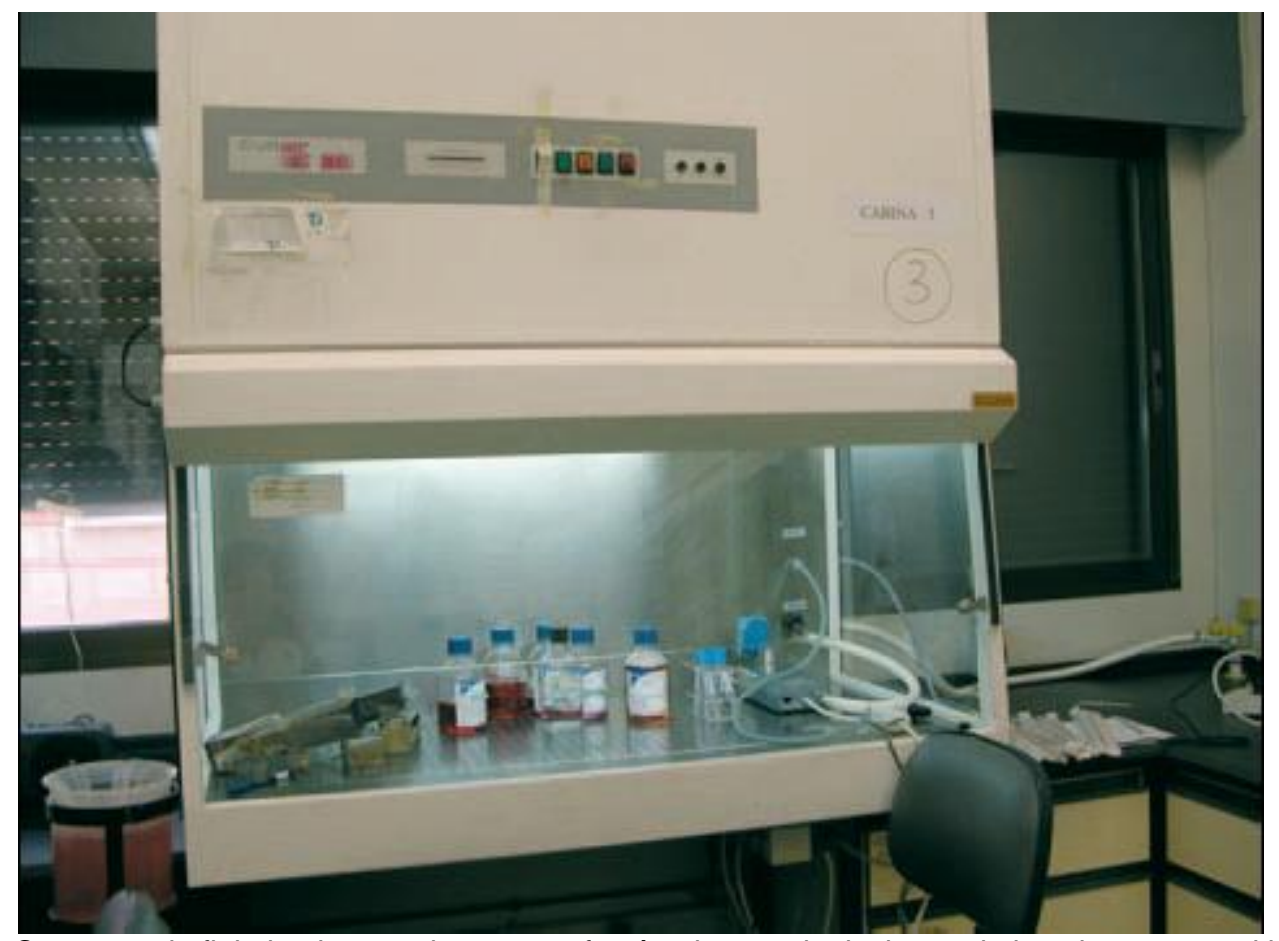

Campana de flujo laminar, en la que se efectúan las manipulaciones de las placas con cultivos celulares en condiciones de asepsia.

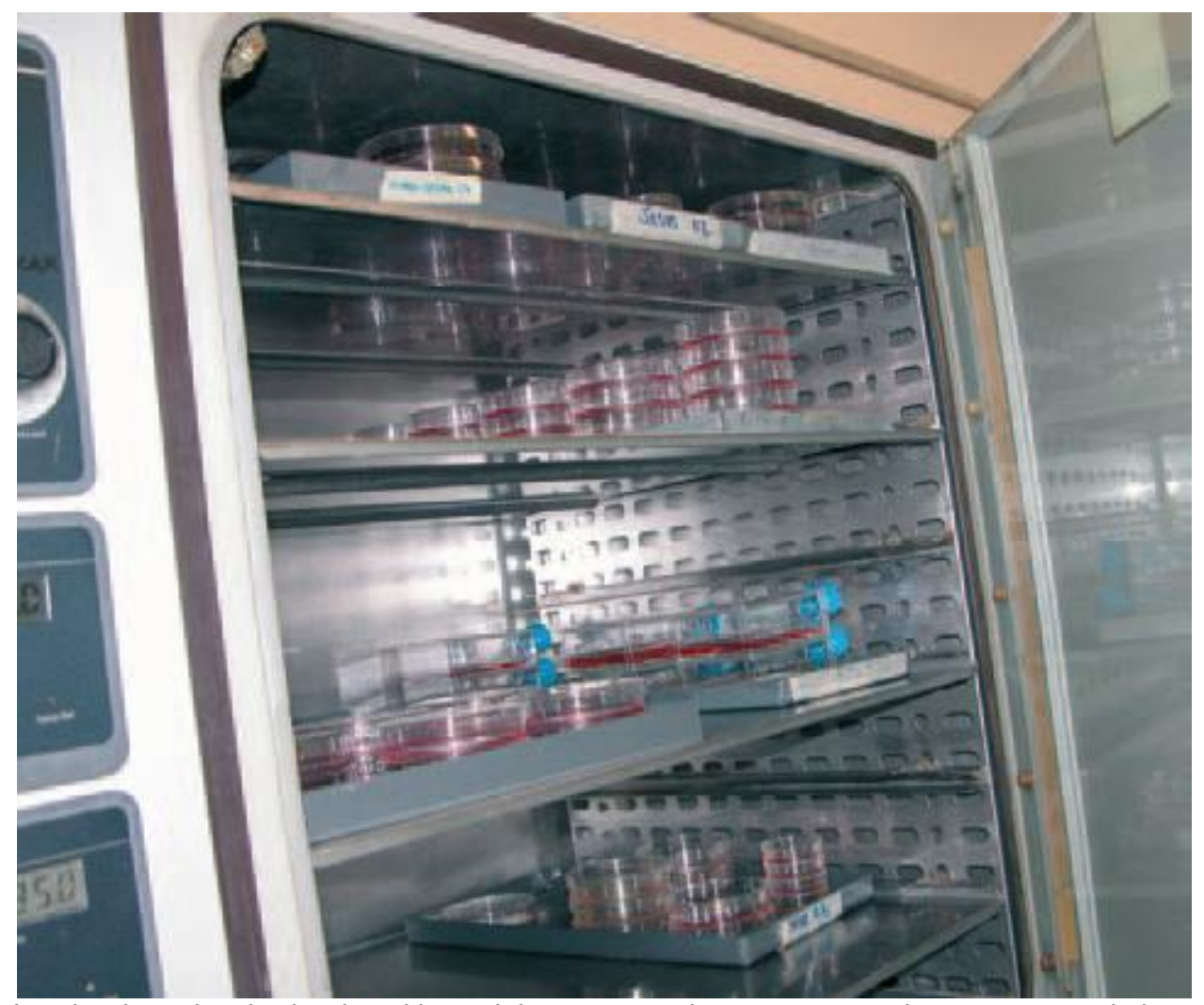

Interior de un incubador de cultivo celular, que mantiene constantes la temperatura, la humedad y la presión de $\mathrm{CO}_{2}$. 